\title{
Autonomous Ration Shops Using Database Management System and Embedded System
}

\author{
Vivek Sharma \\ Ph.D. Scholar \\ Manipal University Jaipur, Jaipur \\ E-mail:- mailtovivek3@gmail.com
}

\begin{abstract}
This paper centres around structure and execution of Automation of Ration Shop. In ongoing situation, all general society and private parts go for computerization in their procedure. Common Supplies Corporation is the significant open segment which oversees and conveys the basic items to all the residents. A portion of the restrictions of traditional proportion shop framework are because of manual estimations in the ordinary framework, consequently the client can not ready to get the precise amount of material. And furthermore there is an opportunity for the unlawful utilization of the items in the regular framework. for example the materials are taken by making incorrectly sections in the register without the information on the apportion card holder. And furthermore the moderate preparing keeps a long line before the shop. To defeat these issues we go for the mechanization of the apportion shops. This article aims for the sequential recording of ration shop transactions to a database using a network of clients with a server. The paper involves a client side and server side. The client PC is the one which is in the ration shop and the server side contains the database and a PC. The client PC is connected with a weighing machine. The client module consists of arduino microcontroller, which is with the weighing machine. The customer with a ration card can have his allotted items and which will be updated to the server as he receives it. The weight of the item is recorded by the microcontroller based weighing machine to the PC. The customer can access the details of his purchase and the amount of items left in the shop through an ASP.NET based webpage. The server stores all the allotted items to a ration shop for each and every customer and also the total items allotted for the ration shop. This project aims in the minimization of ration related corruption including the black-market reselling of goods and also the incorrect weights of items supplied and price related issues..
\end{abstract}

Keywords-Ration automation, DBMS, arduino embedded system

\section{Introduction}

This project aims to reduce the corruption that happens in our current ration supply shops. The aim of this project is to computerize the ration shops and sequentially monitor all the transactions occur in there. The main part of the system is a microcontroller embedded weighing machine, which weighs each material given and stores it to the server. As server is updated after each transaction the account is tallied correctly. The weighing machine uses a PIC16F877A microcontroller with a two line LCD display. This displays the card holder's name and the item. And after weighing it, the next item is shown. The item and its weight are shown in the display. Thus the customer can check the correctness of weight of the item supplied [1].

A coding developed in VB Script is used in the retrieval of serial data from the USART port which is an added feature and one of the difficulties which was met during the project. Also there includes an account for the ration shop in which he can manage his daily transactions. He can maintain the ration shop records like cash book, stock register and travel register. All these are completely done in computers, so that manual errors can be minimized and improper accounts can be monitored. Open appropriation framework (PDS) is food security and food dissemination framework shaped by the Government of India for giving food grains at reasonable rates to poor area of populace in the nation. The framework is together overseen by focal and state government. PDS plan to give the essential food grains for example wheat, rice, sugar and lamp fuel oil to recipients at financed rates. In this framework, focal government buy the grains straightforwardly from ranchers at least help cost and forward required stock from FCI cushions to state government at focal giving value, state government which really oversees PDS at ground level may include state benefits in its territory [2][3].

In the present framework reasonable value shop works at ground level to circulate the proportion to recipients. The present apportion appropriation is completely founded on manual work. To get the month to month apportion one have to present the proportion card, the subtleties of procurement like sum and all out cost alongside date are entered in the card and in the buy register of wholesaler. This manual framework has two disadvantages the apportion given to client might be off base as far as weight in view of mistake presented by human association and besides, if the recipient doesn't accepting the materials for any month, As indicated by the overview done by Planning Commissioning of India [6], PDS 
isn't totally compelling in satisfying the necessary interest of expanding populace. The present framework is increasingly one-sided towards the created locales and can't reach at every single section of nation. The framework doesn't approach districts that are immature which in turns inconsistent development rate in nation. In present executed framework it is hard to check legitimacy of gave card, regardless of whether a card is fake or veritable. Likewise there is no observing at ground level for example at reasonable value shops; seller may to change over the great quality grains got from F.C.I. stock with substandard quality. Vendor is allowed to make counterfeit passages in register and sell the staying stock in open market [4].

The front-end of this project is a website developed in ASP.NET with accounts to every card holder. Every card holder can access his account and check his allotments for a month and if the product is available in their respective ration shops. The administrator privileges of the website are vested with the concerned officer who is to check the accounts. He can access the database and update the data. The inspector can also check the registers within the server system, for each and every ration shop and identify if all the transactions are correct. This will minimize the corruption related issues that happens in our now-a-day ration shops [5].

\section{EXISTING TECHNIQUES}

The existing system consists of manual recording of the data to an account book, which is a rather old technique and can be easily forged. This system does not provide enough proof for the items sanctioned and their proper sales, this was a loophole in the system which allowed the ration shop owners to re-sell the items for a huge price to the retailers instead distributing it to customers. The use of traditional common balance can lead to many forms of cheating. Common balance would not provide the exact weight if it system is properly balanced. The use of extra weights tied to the weighing balance can show wrong weight. So we implement the electronic weighing machine into the concept. In it there is a potentiometer inside and when a weight is added to its pan the deflection in the potentiometer tells the exact weight. Now here in it we add an extra microcontroller unit with the potentiometer. This microcontroller unit takes the weight from the machine and gives it to the LCD display. It also sends this data to the PC. The user could instantly monitor all these as this happens. The ration shop employee could do nothing with the weights or with the stock available. This added feature is proven to reduce corruption to a minimum level [6].
Shubham Mahesh Wari, Mukesh Tiwari proposed a Smart Public Ration Distribution System. They have utilized RFID cards for validation and OTP for security of client. An OTP is sent to client with the assistance of GSM (SIM900). They have overseen client database utilizing MS-SQL DBMS. The entire framework is worked around ARM7 microcontroller for example LPC2148 (takes a shot at 32 piece ARM guidance set). Sana A. Quader Peramapalli, Dr. R. R. Dube introduced a Smart Card e-Public Distribution System. In whichsmartcard,fingerprint verification, and UID number (AADHAR) is utilized asuser's distinguishing proof is. UID number is entered utilizing console and LCD is utilized as show gadget. They have furnished the office of online instalment with the assistance of client's record subtleties. The framework is worked around ARM7 Microcontroller [7].

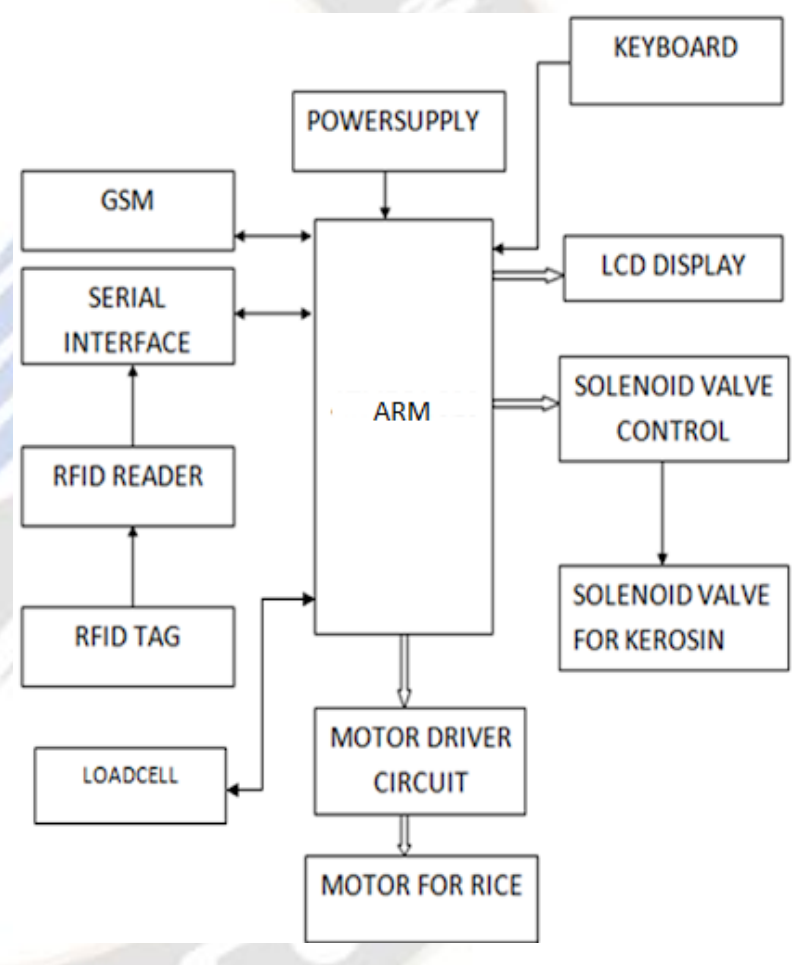

Fig 1: Structure of the existing system

The proposed framework utilizes Raspberry-pi to think about client number put away in My-SQL database with filtered savvy card number. After effective verification the client enters required qualities through console and after exchange, all subtleties of exchange will be sent to client's enrolled versatile number through GSMmodule and thedatabase will be refreshed in like manner. R. Yuvasri, Mrs. R. Sudha, A. Vithya, V. Arthi, K. Thamarai Selvi introduced a Smart Rationing System. The proposed framework contains client ID utilizing brilliant card, LCD as show gadget to show client name, account subtleties and so forth. The entire framework 
is worked around PIC microcontroller. An update message will be sent to client through GSM [10].

\section{Proposed Methodology}

The system being proposed involves full computerization of the ration shops as every transaction is being monitored and saved to the server. The allotted items are saved in the server system. Each ration card holder will be having a password and Radio Frequency Identification (RFID) material. As a person buys an item, the exact weight of the thing given to him will be updated to the server and the remaining stock is shown in the webpage.

The software part of our system consists of three modules :the administrator, user and the ration shop employee.

The administrator module consists of the login page where he could use his admin privileges to verify the registers of each ration shop. He will be asked to enter the ration shop id and when enters he could view the cash book, stock register, travel register and also update the database. The cash book stores all the transactions that happen in the ration shop. The cash book entries are done by the ration shop employee which could be checked by the admin. The stock register keeps record of the stocks that is allotted to the ration shop for a month. The admin could also verify the stocks allotted and also check on the proper selling of products.

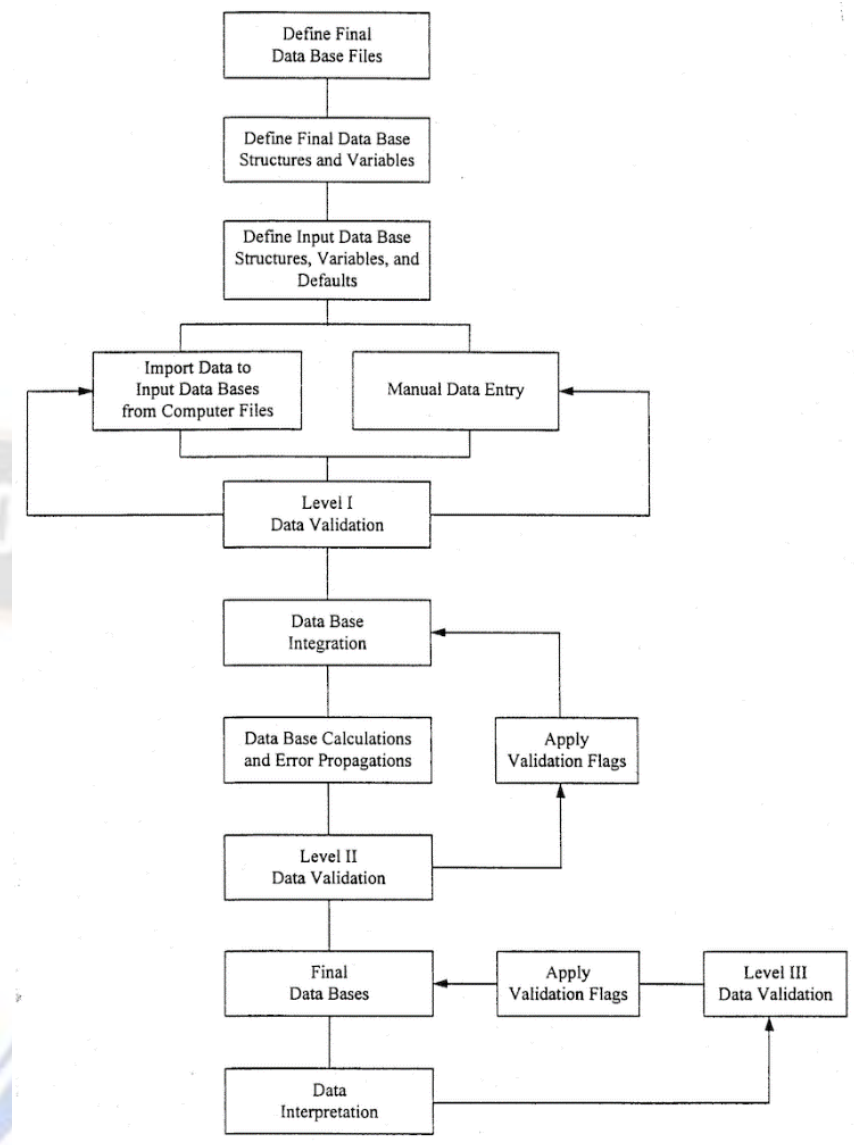

Fig 2: Structure of the proposed database management system

The travel register contains the data of the card holders of that ration shop; the details include the name of the card holder, his family details, and his allotments for a month and so on. The admin can also update the database using his account. The second module is the employee module. The employee logs in to his account. There he has a purchase and records section. He could choose the records section, if he needs to enter his records. Else if he is to sell the items he needs to go to the purchase section. In the purchase section it is the card holder who is to authenticate in the employee's account. The RFID with the user along with his password is used for the login. With a proper login the employee could watch the allotments for a user and provide him the items. After allotting the bill would be provided to the consumer and the data is stored to the database.

The third module is the user's account. The user can access all his details and information through his personal account. Once he logs in within his user id and password he could have access to 'my account' which has all the details about his transactions and his future allotments. There is a section called 'complaints' in which the consumer could post complaints about his ration shops or about corruptions. An 'FAQ' page helps the user at every minute about any 
enquiries. The gauging machine comprises of a gauging container associated with a potentiometer. At the point when weight is included the gauging skillet, the obstruction of the potentiometer is changed. As needs be a fluctuating voltage is given to the microcontroller. The microcontroller utilized in this undertaking is PIC 16F877A. It gets the information from the potentiometer. It additionally ascertains the weight and imparts sign to the PC through sequential port.

USART implies Universal Synchronous Asynchronous Reception and Transmission. It is going about as the interface between the PC and Microcontroller. It utilizes MAX 232 IC. The information from the microcontroller is sent to the PC through USART. The product in the PC is written in ASP Net. The PC shows the weight and client subtleties and furthermore sends to the server through Internet. Therefore the manager can see the information in online way. Every client is given a RF ID Card. The RF ID card is an uncommonly planned card which has inbuilt attractive stockpiling gadget. A particular code is put away in every RF ID card.

The RF ID Sensor is associated with the PC through sequential port. A loop is associated with the sensor Board. When the card is set close to the sensor, the sensor detects the code and imparts sign to the PC through sequential port. The information from the Sensor is given to the PC through sequential port by methods for sequential information. The plan and port projects are written in Visual Basic. The PC gets the information and examinations the information with the put away information. On the off chance that it is an approved client; the present exchange is completed in the PC. All the client and Book subtleties are shown in the PC. Serial communication is not possible from a port to any device, as these are not built in capabilities of net programming.

To include serial communication from the weighing machine through an USART to the PC we need to use the concept of Active Comport. Adding sequential correspondences abilities to an application is rarely a basic issue. It requires specific information that may be outside an individual software engineer's mastery. For a considerable length of time, VBScript, Visual Basic and Visual C++ designers have depended upon the force, adaptability and unwavering quality of the Active Comport sequential correspondences control from Active Xperts Software. What's more, today, likewise .NET designers utilize this control. Active Comport is a COM segment that gives a simple to-utilize scripting interface for sequential, offbeat correspondences through a sequential port. Active Comport can control modems, ISDN modems, USB sequential gadgets and different gadgets and machines that have a sequential interface.
IV. Simulation Results

Before the implementation of the system the cheating in weights were up to $30 \%$ and more. Now after our system has been implemented it is decreased to below 5\%. Up to $95 \%$ correctness is achieved by using our systems. The most common corruptions like stock hiding, over charging, and role of middle men are completely removed from the system. The processing speed in the ration shops are minimized by a half by the total computerization of the shops. Also proper item delivery is done to the customer as the customer itself knows about the stock. The weighing has been made to be accurate as there is only little chance to fraud the electronic weighing machine.

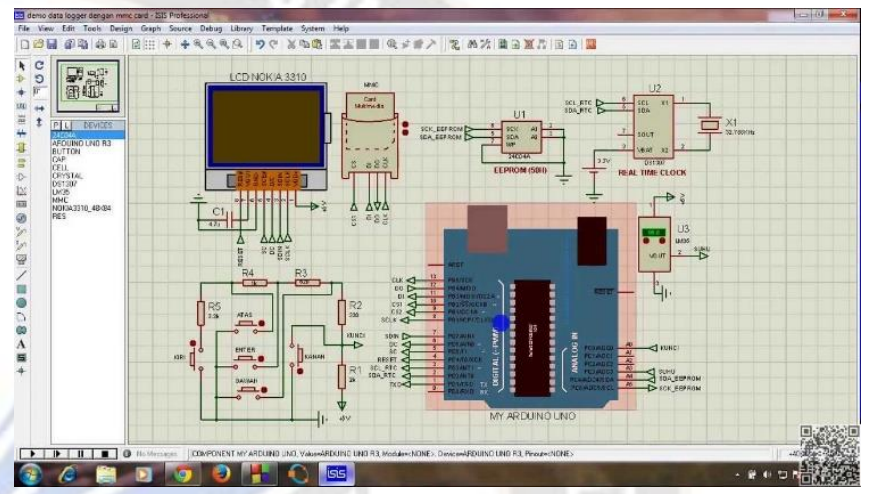

Fig 3: Simulation of the proposed system using proteus

Another achievement of our project is that in the reduction of work load of the ration shop keeper. As all the system is computerized he could manage his accounts easily and efficiently. The inspector could check and validate the accounts of the ration shops under his control and minimize the journeys and can process much information by saving time. The complaint box proves to be useful when there is corruption and the government could open consumer help lines for the help of illiterate consumers. The login page developed is shown in figure 4 .

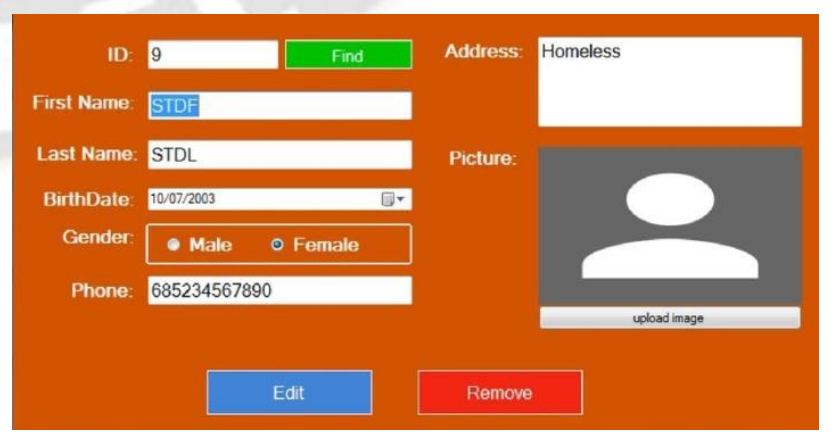

Fig 4: Login window showing credentials 
The corruption in our public distribution system is around Rs.370 Crores per annum. By implementing our project, it could be minimized to below Rs.50 Crores. This system could help the poor and the below poverty line population to be sustainable and self sufficient; because the current corruption mostly affects the middle class and lower middle class people. However the problems related to distribution of old stock and low quality stock cannot be controlled. This could be controlled only if the government follows strict checking methods. If this can be done then the corruption rate may even fall a considerable rate.

It is estimated that about Rs. 358 Crore is the total value of corruption in the public distribution system every year in India. By implementing our system it could be minimized under Rs. 50 Crore. Thus the total corruption could be minimized up to $85 \%$ from the current status. A cent percent corruption free PDS could be achieved by the active participation of the governments by frequent raids and checking. This could ultimately reduce the economic problems of farmers and ultimately boost the country's economy. Production and supply of goods can be monitored and wastage of food crops can be avoided. Government aided farming especially for the public distribution system can be implemented further. The future implementations of our project include the usage of online transactions through the net banking facility of the shopkeeper. And also reviving the public distribution system by a revival of the ration cards by including the neediest one's who needs ration and to avoid the people who don't use their ration shop allotments. The ultimate aim of self-sustainability can be achieved by our project also by including its future enhancements.

\section{Conclusion}

The main aim of this project as discussed earlier, which is to reduce the corruption, could be achieved by the proper implementation of our project. It is estimated that about $85 \%$ of the corruption related issues can be eliminated through this system. The rest however is depending upon the quality of the products sold, which could also be controlled, if the government takes proper measures to monitor the Public Distribution System. Frequent checking of the stock and items must be done for this. The age old problem related to the weight of items sold is eliminated by the electronic weighing machine and also proper recording of data provides a stable and efficient system for the registering of records. Long queues and waiting in front of the shops are now eliminated, since the automated process can minimize the time needed to verify the accounts and registers are minimized by the automated system. Steady price can be maintained by using this system, the government can have a control over the commodity prices no matter how the economy changes. Direct from farmer method can be implemented as it is now in the milk co-operative society.

\section{References}

[1] Basanta Kumar, Brajraj Mohanty, "Public Distribution System in Rural India: Implications for Food Safety and Consumer Protection", Procedia - Social and Behavioral Sciences, International Congress on Interdisciplinary Business and Social Science 2012 (ICIBSoS-2012), pg. $232-238$

[2] Chang-Lung Tsai, Chun-Jung Chen. "Trusted M-banking Verification Scheme based on a combination of OTP and Biometrics", Journal of Convergence, Vol 3,No. 3, pg.2330, 2012

[3] Sana A. Qader Perampalli1, Dr. R.R. Dube2,॥ Smart Card based e-Public Distribution Systemll, International Journal of Advanced Research in Computer and Communication Engineering Vol. 5, Issue 5, May 2016.

[4] Qian Tonghui, Qi Yang, Cai Limin, Shi Zili, Cui Xiaowu and $\mathrm{Li}$ Dehua, "The design of embedded database management system for mobile computing," 2012 International Conference on Computer Science and Information Processing (CSIP), Xi'an, Shaanxi, 2012, pp. 1454-1457, doi: 10.1109/CSIP.2012.6309139.

[5] Kumbhar Aakanksha, Kumavat Sukanya, Lonkar Madhuri, Mrs. A.S. Pawar, Smart Ration Card System Using Raspberry-pi -,International Journal of Advanced Research in Computer and Communication Engineering Vol. 5, Issue 4, April 2016.

[6] R. Yuvasri A. Vithya K. Thamarai Selvi Mrs. R. Sudha V. Arthi „ISmart Rationing System\|, International Journal For Trends In Engineering \& Technology Volume 14 Issue 1 - June 2016 - ISSN: 2349 - 9303.

[7] C. Chandankhede and D. Mukhopadhyay, "A proposed architecture for automating public distribution system," 2017 International Conference on Computing, Communication and Automation (ICCCA), Greater Noida, 2017, pp. 935-939, doi: 10.1109/CCAA.2017.8229941.

[8] Y. Wu, "Design of User Database Resource Management System Based on Web," 2017 International Conference on Computer Technology, Electronics and Communication (ICCTEC), Dalian, China, 2017, pp. 364-367, doi: 10.1109/ICCTEC.2017.00084.

[9] Z. J. Zhang, "Graph Databases for Knowledge Management," in IT Professional, vol. 19, no. 6, pp. 2632, November/December 2017, doi: 10.1109/MITP.2017.4241463.

[10] X. Jiang and G. Song, "The database design for the control equipment management system," 2012 3rd International Conference on System Science, Engineering Design and Manufacturing Informatization, Chengdu, 2012, pp. 261264, doi: 10.1109/ICSSEM.2012.6340859. 